\title{
Long non-coding RNA HOXB-AS3 promotes myeloid cell proliferation and its higher expression is an adverse prognostic marker in patients with acute myeloid leukemia and myelodysplastic syndrome
}

\author{
Huai-Hsuan Huang ${ }^{1,3}$, Fei-Yun Chen ${ }^{4}$, Wen-Chien Chou ${ }^{1,2}$, Hsin-An Hou' ${ }^{1}$, Bor-Sheng Ko ${ }^{1}$, Chien-Ting Lin ${ }^{5}$,
} Jih-Luh Tang ${ }^{1,5}$, Chi-Cheng Li ${ }^{5}$, Ming Yao ${ }^{1}$, Woei Tsay ${ }^{1}$, Szu-Chun Hsu², Shang-Ju Wu', Chien-Yuan Chen', Shang-Yi Huang ${ }^{1}$, Mei-Hsuan Tseng ${ }^{1}$, Hwei-Fang Tien ${ }^{1,3^{*+}}$ and Ruey-Hwa Chen ${ }^{3,4^{*+}+}$

\begin{abstract}
Background: Long non-coding RNAs (IncRNAs) represent the majority of cellular transcripts and play pivotal roles in hematopoiesis. However, their clinical relevance in acute myeloid leukemia (AML) and myelodysplastic syndrome (MDS) remains largely unknown. Here, we investigated the functions of HOXB-AS3, a IncRNA located at human HOXB cluster, in the myeloid cells, and analyzed the prognostic significances in patients with AML and MDS.

Methods: shRNAs were used to downregulate HOXB-AS3 in the cell lines and the effect was evaluated by quantitative polymerase chain reaction. The proliferation of the cell lines was illustrated by proliferation and BrdU flow assays. Further, we retrospectively analyzed the HOXB-AS3 expression in 193 patients with AML and 157 with MDS by microarray analysis, and evaluated its clinical importance.

Results: Downregulation of HOXB-AS3 suppressed cell proliferation. Mechanistically, HOXB-AS3 potentiated the expressions of several key factors in cell cycle progression and DNA replication without affecting the expressions of HOX genes. In AML, patients with higher HOXB-AS3 expression had shorter survival than those with lower HOXB-AS3 expression (median overall survival (OS), 17.7 months versus not reached, $P<0.0001$; median relapse-free survival, 12.9 months versus not reached, $P=0.0070$ ). In MDS, patients with higher HOXB-AS3 expression also had adverse prognosis compared with those with lower HOXB-AS3 expression (median OS, 14.6 months versus 42.4 months, $P=0.0018$ ). The prognostic significance of HOXB-AS3 expression was validated in the TCGA AML cohort and another MDS cohort from our institute. The subgroup analyses in MDS patients showed that higher HOXB-AS3 expressions could predict poor prognosis only in lower-risk (median OS, 29.2 months versus 77.3 months, $P=0.0194$ ), but not higher-risk group.
\end{abstract}

Conclusions: This study uncovers a promoting role of HOXB-AS3 in myeloid malignancies and identifies the prognostic value of HOXB-AS3 expression in AML and MDS patients, particularly in the lower-risk group.

Keywords: HOXB-AS3, Acute myeloid leukemia, Myelodysplastic syndrome

\footnotetext{
* Correspondence: hftien@ntu.edu.tw; rhchen@gate.sinica.edu.tw

${ }^{\dagger}$ Hwei-Fang Tien and Ruey-Hwa Chen contributed equally to this work.

${ }^{1}$ Division of Hematology, Department of Internal Medicine, National Taiwan

University Hospital, Taipei, Taiwan

${ }^{3}$ Doctoral Degree Program in Translational Medicine, National Taiwan

University and Academia Sinica, Taipei, Taiwan

Full list of author information is available at the end of the article
}

(c) The Author(s). 2019 Open Access This article is distributed under the terms of the Creative Commons Attribution 4.0 International License (http://creativecommons.org/licenses/by/4.0/), which permits unrestricted use, distribution, and reproduction in any medium, provided you give appropriate credit to the original author(s) and the source, provide a link to the Creative Commons license, and indicate if changes were made. The Creative Commons Public Domain Dedication waiver (http://creativecommons.org/publicdomain/zero/1.0/) applies to the data made available in this article, unless otherwise stated. 


\section{Background}

Acute myeloid leukemia (AML) and myelodysplastic syndrome (MDS) are two myeloid malignancies [1] which share similar somatic gene mutations [2]. A portion of MDS patients eventually progresses to AML as the disease progresses. Several prognostic models have been developed to better risk stratify AML and MDS patients, such as European Leukemia Net (ELN) risk classification for AML [3] and international prognostic scoring system (IPSS) or revised IPSS (IPSS-R) for MDS [4-8]. However, patients may have different prognosis even in the same risk group [9-12]. Exploration of more markers that have prognostic significance are warranted to better risk stratify patients with the diseases.

Long non-coding RNAs (lncRNAs) are transcripts longer than 200 nucleotides without protein coding ability. The functions of most lncRNAs remain poorly characterized, but some of them have been demonstrated to be involved in the hematopoiesis [13-15]. For example, the expression levels of HOTAIRM1 and NEAT1 are elevated during myeloid differentiation, and downregulation of HOTAIRM1 or NEAT1 delays myeloid maturation [13, 14]. Expression of $X I S T$, a lncRNA at X chromosome, inactivates $\mathrm{X}$ chromosome in the female cells. The female mice with deletion of Xist develop a highly aggressive disease mimicking MDS/ MPN [15]. However, the roles of lncRNAs in MDS remain largely unknown [16], and only a few research investigated the role of IncRNAs in de novo AML [17-19]. In the research aimed to find prognostic biomarkers in acute myeloid leukemia (AML), we found expression of $H O X B-A S 3$, a lncRNA located at human $H O X B$ cluster, is a potential risk factor. However, its clinical relevance and pathogenesis in AML and MDS remain to be determined.

Here, we demonstrate that high expression of HOXB$A S 3$ is an adverse prognostic factor for both de novo AML and primary MDS patients. Furthermore, the expression of $H O X B-A S 3$ promotes cell proliferation in myeloid cells.

\section{Methods}

\section{Patients}

We retrospectively included the adult patients with newly diagnosed primary MDS and de novo AML at the National Taiwan University Hospital (NTUH) from 1992 to 2010. Among them, 157 MDS and 193 AML patients, who had available cryopreserved bone marrow (BM) cells for RNA array analysis and comprehensive clinical information, were recruited for this study. The Cancer Genome Atlas (TCGA) AML cohort available on the TCGA website (https://cancergenome.nih.gov/) and an independent cohort of 30 MDS patients subsequently diagnosed between January 2011 and May 2012 at the NTUH was served as the validation cohorts.
All patients with AML other than acute promyelocytic leukemia (non-APL AML, $n=174$ ) underwent standard induction chemotherapy (Idarubicin $12 \mathrm{mg} / \mathrm{m}^{2}$ per day for two to 3 days and Cytarabine $100 \mathrm{mg} / \mathrm{m}^{2}$ per day for five to 7 days), and consolidation chemotherapy with two-to-four courses of high-dose Cytarabine $(2000 \mathrm{mg} /$ $\mathrm{m}^{2}$ every twelve hours for 4 days, total eight doses), with or without an anthracycline (idarubicin or mitoxantrone), after they achieved complete remission (CR) as described in our previous studies [20]. Nineteen APL patients received concurrent all-trans retinoic acid (ATRA) and Idarubicin or Mitoxantrone as induction chemotherapy and ATRA with Idarubicin, Mitoxantrone or high dose Cytarabine as consolidation chemotherapy when they achieved CR. If the patients had relapsed or refractory AML, or adverse prognostic factors at diagnosis, such as adverse-risk cytogenetic abnormalities or somatic gene mutations, they underwent allogeneic hematopoietic stem cell transplantation (allo-HSCT) when they had feasible hematopoietic stem cell donors.

In the NTUH MDS training cohort, most MDS patients $(70.7 \%)$ only received supportive care. Eight patients (5.1\%) received AML-directed intensive chemotherapies, $18(11.5 \%)$ received hypomethylating agent (azacitadine or decitabbine), and 20 patients (12.7\%) underwent allo-HSCT.

The BM samples from AML and MDS patients were collected at diagnosis, and the mononuclear cells were isolated by Ficoll-Hypaque gradient centrifugation and cryopreserved as previously described [21, 22]. The BM cells from 20 healthy transplantation donors were used as the normal controls to compare the gene expressions with those of AML and MDS patients. This study was approved by the Institutional Review Board of NTUH (IRB number: 201507084RINA and 201503072RINC). All the patients have signed informed consents for the collection of samples and clinical information.

Analysis of cytogenetic abnormalities and gene mutations The BM cells were harvested directly or after one to 3 days of un-stimulated cultures. The metaphase chromosomes were banded by the G-banding method as previously described. [23] The determination of mutations in NPM1 [21, 24], AML1 (RUNX1) [25], ASXL1 [26], DNMT3A [20], EZH2 [27], IDH2 [28], NRAS [29], KRAS [29], TP53 [30], SETBP1 [31], SRSF2 [32], TET2 [33], $M L L / P T D$ [34], SF3B1 [35], U2AF35 [36], and ZRSR2 [35] was performed as described previously.

\section{Microarray experiments and analysis}

The raw data of TCGA AML cohort was downloaded from TCGA website (https://cancergenome.nih.gov/). The detail methods of microarrays for NTUH AML and NTUH MDS cohorts were described in Additional file 1. 
The expression levels of two transcript clusters, TC17002254.hg.1 and TC17002858.hg.1, on Affymetrix GeneChip ${ }^{\circ}$ HTA 2.0 represent HOXB-AS3 (NCBI Reference Sequence: NC_000017.11) expression. TC17002254.hg.1 detects variants 1 to 5 of $H O X B-A S 3$, and TC17002858.h. 1 detects all variants of $H O X B-A S 3$. Because TC17002858.h. 1 detects all $H O X B-A S 3$ variants and the expression pattern was similar between the two transcript clusters, expression of TC17002858.hg.1 was used to stratify patients.

\section{Cell lines, cell cultures, and associated experiments}

OCI/AML3 and TF-1 were human myeloid leukemia cell lines. TF-1 cell line (BCRC number 60323) was purchased from Bioresource Collection and Research Center (BCRC), Hsinchu, Taiwan on Sep 29, 2014. BCRC (http://www.bcrc.firdi.org.tw/) is a nation-wide cell bank in Taiwan, and it provides the service of preservation, identification, and selling of cell lines. OCI/AML3 was a gift from Dr. Minden (Ontario Cancer Institute/Princess Margaret Hospital, Canada) in 2008. The detailed methods of cell cultures, constructions of lentiviral vectors with shRNA and lncRNA, lentiviral production, lentiviral infections, quantitative real time PCR, proliferation assay and nuclear-cytoplasm fractionation were described in Additional file 1.

\section{BrdU flow assay}

BD Pharmingen $^{\text {тм }}$ APC BrdU Flow Kits (Cat. NO. 552598) was used for BrdU flow assay. Cells were incubated with $10 \mu \mathrm{M} \mathrm{BrdU}$ at $37^{\circ} \mathrm{C}$ for three hours, and then harvested for BrdU flow assay. The detailed method was described in the user manual of the manufacture. The flow cytometry was performed on LSR II (BD Bioscience, San Jose, CA) through the service provided by the Flow Cytometric Analyzing and Sorting Core Facility at the NTUH, and on FACS Canto II (BD Bioscience, San Jose, CA) through the service provided by the Molecular and Immune Function Laboratory at Tai Cheng Stem Cell Therapy Center at the National Taiwan University.

\section{Statistical analysis}

Mann-Whitney test was used to calculate the significance if the continuous data were not normally distributed, and Kruskal-Wallis test was used for comparing the difference between more than two groups. Chisquare test was used to calculate the significance of association between $H O X B-A S 3$ expression and other categorical parameters, including sex, IPSS risk groups, 2016 WHO subtypes, cytogenetic abnormalities, and gene mutations. Fisher exact test was used if any expected value of the contingency table was less than five.

For patients with de novo AML in the NTUH AML cohort, overall survival (OS) was measured from the date of diagnosis to the date of last follow-up or death. The patients were censored on the date of last follow-up if they were alive. Relapse free survival (RFS) was defined from the date of complete remission to the date of relapse, last follow-up, or death. Relapse and death were defined as events in the RFS analysis. If the patients were alive and in complete remission, they would be censored. For patients with primary MDS, OS was measured from the date of diagnosis to the date of last follow-up or death. The patients were censored on the date of last follow-up if they were alive.

Kaplan-Meier (KM) estimation was used to plot survival curves, and log-rank tests were used to calculate the difference of OS and RFS between different groups in AML patients and OS in MDS patients. Median follow-up duration was calculated by reverse KM estimation. Multivariate Cox proportional hazard regression analysis was used to investigate independent prognostic factors for OS. A $P$ value less than 0.05 was considered statistically significant. All statistical analyses were performed with MedCalc ${ }^{\oplus} 15.6 .1$ software (https:// www.medcalc.org/).

\section{Results \\ $H O X B-A S 3$ is an anti-sense IncRNA in the HOXB cluster}

In order to find lncRNAs with significant prognostic implications in myeloid malignancies, we analyzed the microarrays data from two cohorts: one AML cohort from the NTUH (NTUH AML cohort), and another one from The Cancer Genome Atlas (TCGA AML cohort) [37]. The expression of 2824 probes in TCGA AML cohort and 4454 transcript clusters in NTUH AML cohort had prognostic significance (Fig. 1a). The intersect between the two cohorts was 907 probes/transcript clusters, among which eleven lncRNAs were validated as noncoding RNAs according to National Center for Biotechnology Information (NCBI) database (Fig. 1a). Among these lncRNAs, $H O X B-A S 3$ is particularly interesting, because of the crucial roles of $H O X$ genes in cell proliferation, hematopoiesis and leukemogenesis [36, 38, 39] and the clinical significance of an anti-sense lncRNA in the HOX clusters, i.e., HOTAIRM1, in leukemia [40]. Since the role of IncRNAs in myeloid malignancies remains unclear, the following studies were focused on the role of $H O X B-A S 3$ in myeloid malignancies.

$H O X B-A S 3$ is a lncRNA located at human $H O X B$ cluster on the chromosome $17 \mathrm{q} 21.32$ and has eight transcriptional variants generated by alternative splicing (Fig. 1b). The entire gene is overlapped with HOXB5 and HOXB6 genes, and the transcriptional direction is antisense to the overlapping $H O X B$ genes (Fig. 1b). The exons of $H O X B-A S 3$, except for exon 2, are not overlapped with the exons of HOXB5 or HOXB6 (Fig. 1b). 


$$
\text { a }
$$

\section{TCGA}

AML cohort

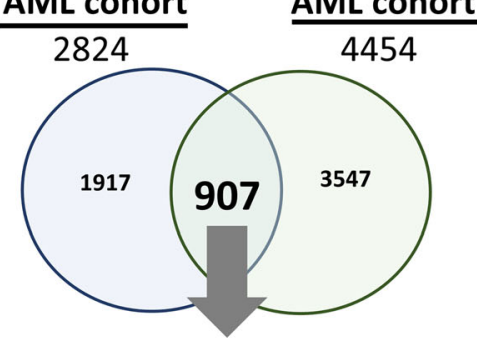

Validated non-coding RNA

\begin{tabular}{|ccc|}
\hline Symbol & Prognosis & Chromosome \\
\hline A2M-AS1 & Adverse & $12 \mathrm{p} 13.3$ \\
\hline BZRAP1-AS1 & Favorable & $17 \mathrm{q} 22$ \\
\hline HOXB-AS3 & Adverse & $7 \mathrm{p} 15.2$ \\
\hline LINC00299 & Adverse & $2 \mathrm{p} 25.1$ \\
\hline LINC00899 & Adverse & $22 \mathrm{q} 13.31$ \\
\hline LINC00926 & Favorable & $15 \mathrm{q} 21.3$ \\
\hline LINC00963 & Adverse & $9 \mathrm{q} 34.11$ \\
\hline LINC00982 & Adverse & $1 \mathrm{p} 36.32$ \\
\hline LOC646762 & Favorable & $7 \mathrm{p} 14.3$ \\
\hline TRAF3IP2-AS1 & Favorable & $6 \mathrm{q} 21$ \\
\hline ZSWIM8-AS1 & Favorable & $10 \mathrm{q} 22.2$ \\
\hline
\end{tabular}

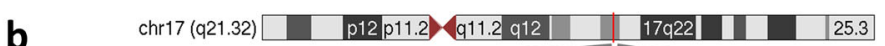

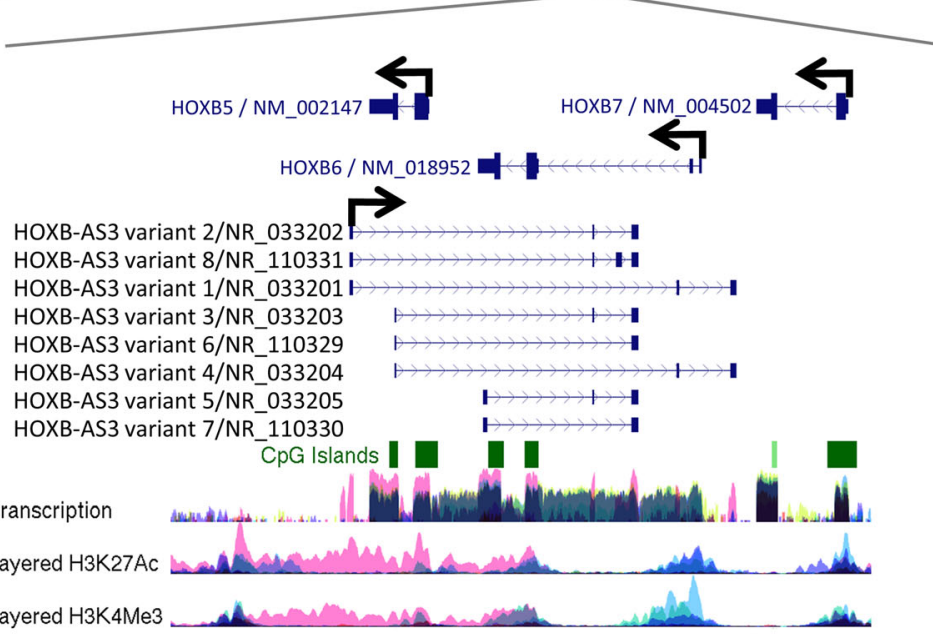

C

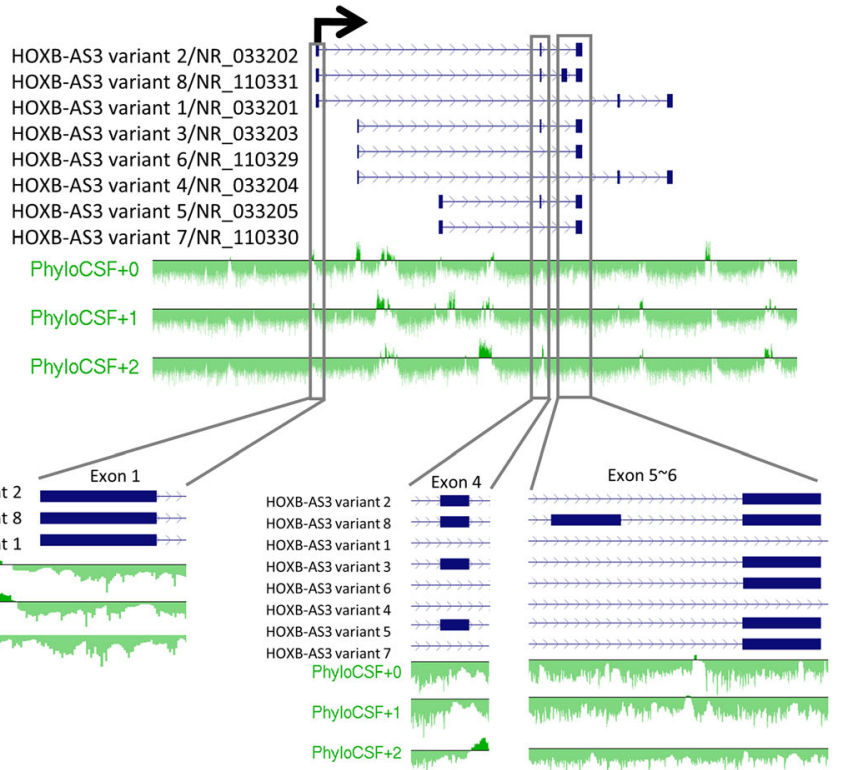

Fig. 1 Identification of HOXB-AS3 as a prognostic biomarker and overview of its locus in human HOXB. a The numbers of genes influenced overall survival in TCGA AML cohort and NTUH AML cohort. $\mathbf{b}$ The neighborhood of HOXB-AS3 locus in human HOXB cluster. The genomic data from ENCODE project was taken from UCSC genome browser. The exon localizations of eight HOXB-AS3 isoforms and HOXB5, HOXB6, and HOXB7 genes are shown. Arrows indicate the transcription direction of these genes. The NCBI Reference Sequence (RefSeq) numbers were labeled in the end of each variant. c PhyloCSF analysis for predicting the noncoding nature of HOXB-AS3. Exon 1, exon 4, exon 5 and exon 6 are zoom-in to see the details of PhyloCSF scores of the specific exons. All PhyloCSF scores are negative in the exons of HOXB-AS3

By using PhyloCSF pipeline, HOXB-AS3 is predicted to be a noncoding RNA (Fig. 1c), and the coding probability is low (0.126) by Coding Potential Assessment Tool (CPAT) [41]. Therefore, HOXB-AS3 is an anti-sense lncRNA in the HOXB cluster, similar to HOTAIR in the HOXC cluster, and HOTTIP and HOTAIRM1 in the HOXA cluster [13, 42, 43].

A similar anti-sense transcript, Hoxb5os (NCBI Reference Sequence: NR_131758.1), exists in the mouse
HOXB cluster on chromosome 11 (NCBI Reference Sequence: NC_000077.6 Chromosome 11 Reference GRCm38.p4 C57BL/6 J), and is also predicted to be a lncRNA (Additional file 1: Figure S1). We aligned the sequences of human HOXB-AS3 with that of mouse Hoxb5os by plalign (http://fasta.bioch.virginia.edu/) and observed two conserved regions (Additional file 1: Figure S2), one in exon 1 and the other in exon 6 of $H O X B-A S 3$. These analyses indicated that HOXB-AS3 
might be an evolutionarily conserved anti-sense transcript in the $H O X B$ cluster in mammals.

HOXB-AS3 is a cytoplasmic IncRNA and promotes cell proliferation by increasing the expressions of genes involved in cell cycle progression and DNA replication To investigate the function of $H O X B-A S 3$, we infected the myeloid cell line OCI/AML3 using lentivirus carrying control or each of the two HOXB-AS3 shRNAs together with GFP. The infected cells were sorted for proliferation assay. We found that the cells carrying HOXB-AS3 shRNA grew more slowly than those carrying control shRNA (Fig. 2a). The result suggested the anti-proliferative effect resulted from $H O X B-A S 3$ depletion. To corroborate this effect, we stably knocked down $H O X B-A S 3$ in two myeloid cell lines, OCI/AML3 and
TF-1 (Fig. 2b and d). Downregulation of HOXB-AS3 suppressed the proliferation of OCI/AML3 and TF-1 cells by decreasing the cells entering the $\mathrm{S}$ phase (Fig. 2c and e; Additional file 1: Figure S3a and S3b). Compared with OCI/AML3 cells, the milder effect of $H O X B-A S 3$ depletion in TF-1 cells was possibly resulted from the very low expression of $H O X B-A S 3$ in TF-1 cells (Additional file 1: Figure S3d). In the reciprocal experiments, overexpression of $H O X B-A S 3$ in TF-1 cell line enhanced cell proliferation by promoting cells entering the $\mathrm{S}$ phase (Fig. $2 \mathrm{f}$ and g; Additional file 1: Figure S3c). These findings indicated that $H O X B-A S 3$ promoted cell proliferation in the myeloid cell lines.

To explore the mechanisms of $H O X B-A S 3$ in proliferation, we investigated the expression of genes influenced by $H O X B-A S 3$ depletion through the microarray analysis. We compared the gene expression profiles of $\mathrm{OCI} /$
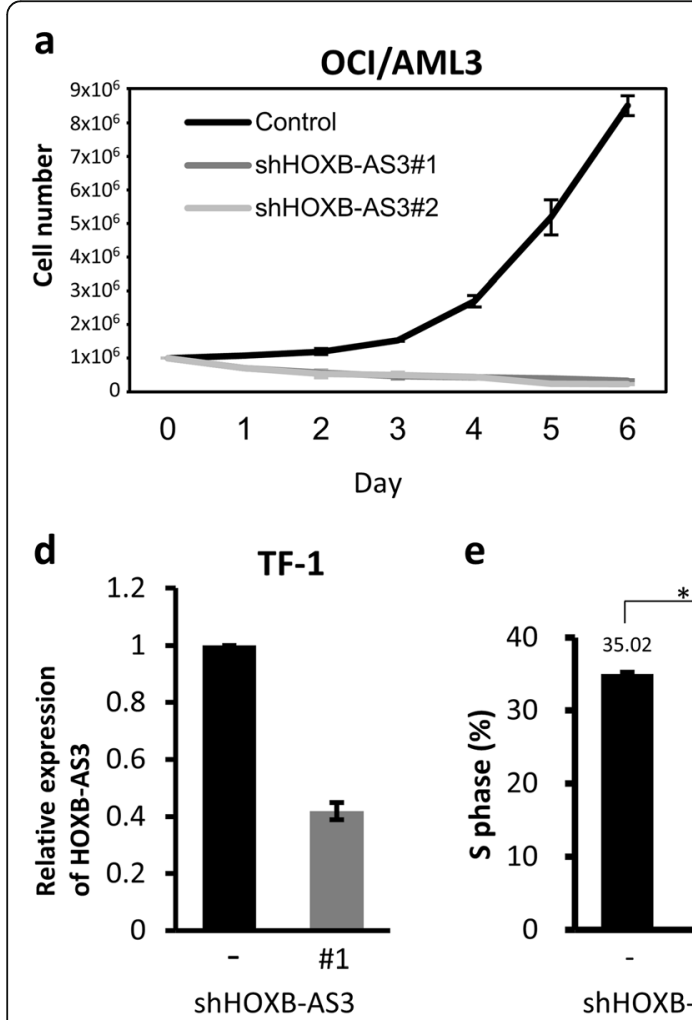
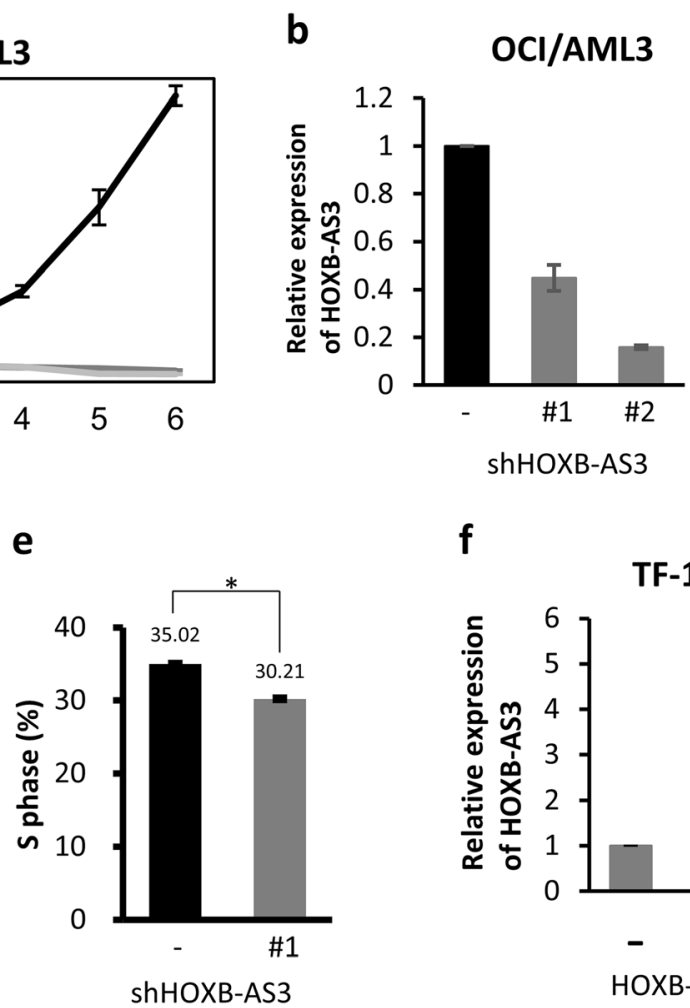

f

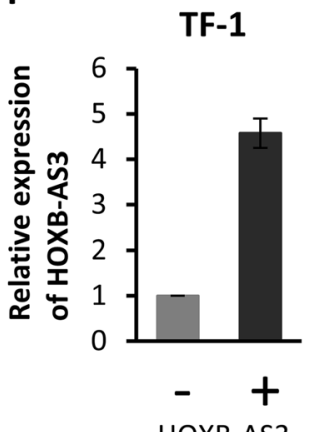

overexpression

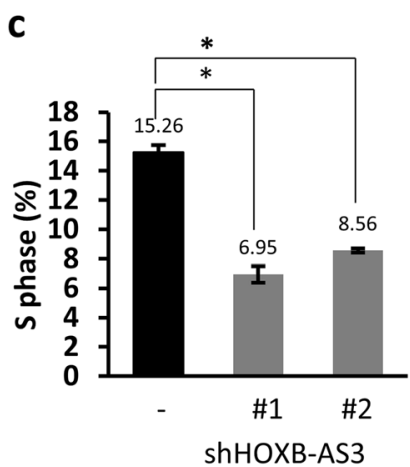

g

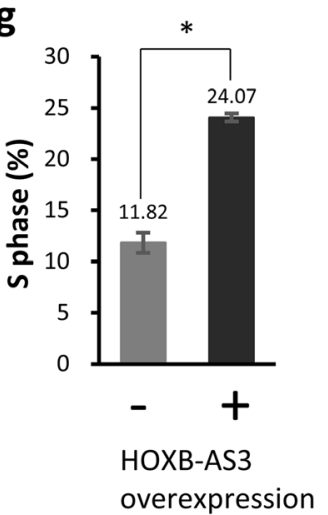

Fig. 2 HOXB-AS3 promotes cell proliferation in myeloid cells. a Proliferation assay of OCI/AML3 cells infected with lentivirus carrying pLKO-vector (control), shHOXB-AS3\#1, or shHOXB-AS3\#2. The infected cells were sorted by the expression of GFP. The sorted GFP-positive cells were seeded with a number of $1 \times 10^{6}$ in $5 \mathrm{~mL}$ culture medium on Day 0 . Cell number was counted for 6 days. $P$ values were calculated by Kruskal-Wallis test. b Quantitative PCR analysis of HOXB-AS3 relative to $\beta 2$ microglobulin expression in OCI/AML3 cells stably carrying pLKO-vector (control), shHOXBAS3\#1, or shHOXB-AS3\#2 by lentivirus infection. c The percentage of OCl/AML3 cells in the $S$ phase of cell cycle. The result was derived from triple repeats. $P$ values were calculated by Kruskal-Wallis test. d Quantitative PCR analysis of HOXB-AS3 relative to $\beta 2$ microglobulin expression in TF-1 cells stably carrying pLKO-vector (control) or shHOXB-AS3\#1 by lentivirus infection. e The percentage of TF-1 cells in the $S$ phase of cell cycle. The result was derived from triple repeats. $P$ values were calculated by Student t test. $\mathbf{f}$ Quantitative PCR analysis of $H O X B$ - $A S 3$ relative to $\beta 2$ microglobulin expression in TF-1 cells infected with lentivirus carrying pLAS5w.Pbsd vector (control) or pLAS5w.Pbsd-HOXB-AS3 (HOXB-AS3 overexpression). $\mathbf{g}$ The percentage of cells in the $\mathrm{S}$ phase of cell cycle. The result was derived from the triple repeats. $P$ values were calculated by Student $t$ test. ${ }^{*}$ meant that $P$ value was less than 0.05 ) 
AML3 cells infected by virus carrying shHOXB-AS3 (two stable cell lines infected with different shHOXBAS3, shHOXB-AS3\#1 or shHOXB-AS3\#2) with those infected by control virus (two stable cell lines infected with shLacZ or pLKO vector).

We compared the gene expressions of $H O X$ clusters between OCI/AML3 cells with and without HOXB-AS3 depletion because previous studies showed that most lncRNAs in $H O X$ clusters are located in the nucleus and regulate the expressions of $H O X$ genes in cis- or transmanner $[42,43]$. However, we found that the expressions of $H O X$ clusters were not influenced by $H O X B$ AS3 depletion (Fig. 3a). Instead, we identified 147 genes and 790 transcript clusters differentially expressed when HOXB-AS3 was knocked down in OCI/AML3 cells (Fig. 3b; the criteria were that the fold change of average $\log 2$-transformed gene expressions was more than 1.5, and that ANOVA $P$ value was less than 0.05 . The analysis was computed by BRB array tool.). GSEA analysis revealed that these differentially expressed genes were involved in several pathways associated with cell cycle progression and DNA replication (Fig. 3c and Additional file 1: Figure S4). Wikipathway analysis computed by Affymetrix ${ }^{\circ}$ TAC also showed that many differentially expressed genes were involved in cell cycle pathway, DNA replication, G1-S transition, and RB pathway (Additional file 1: Figure S5-S8). Moreover, the expressions of these genes were mostly downregulated when $H O X B-A S 3$ was knocked down, consistent with a promoting function of this lncRNA in cell proliferation.

We validated a set of $H O X B-A S 3$ regulated genes by RT-qPCR and confirmed that several genes involved in the cell cycle progression (CDK1, CCNB2, and CDC25A), DNA replication (PCNA), and assembly of pre-replicative complex (CDC6, MCM4, MCM6) were indeed downregulated when $H O X B-A S 3$ was knocked down (Fig. 3d). Conversely, these genes were upregulated when $H O X B-A S 3$ was overexpressed (Additional file 1: Figure S9). These findings suggested that $H O X B$ $A S 3$ induced the expression of a number of genes involving in cell cycle progression and DNA replication to contribute to myeloid cell proliferation.

Furthermore, to identify the subcellular location of IncRNA HOXB-AS3, we used nuclear-cytoplasm fractionation to purify RNA from the nucleus and cytoplasm of OCI/AML3 cells, followed by reverse transcription and quantitative real time PCR. Our analysis demonstrated that the majority of $H O X B-A S 3$ was located at the cytoplasm, different from the nuclear-residing MALAT1 and NEAT1 (Fig. 3e) [44, 45]. Therefore, our results suggest that $H O X B-A S 3$ regulate the expressions of downstream genes through an indirect mechanism, which was different from other anti-sense lncRNAs in the $H O X$ clusters.

\section{Higher HOXB-AS3 expression is associated with shorter overall survival and progression free survival in AML patients}

To determine the clinical significance of HOXB-AS3 in de novo AML patients, we analyzed the microarrays and clinical data of the NTUH AML cohort and validated the results with TCGA AML cohort. In the NTUH AML cohort, HOXB-AS3 expression was determined based on the expression levels of TC17002858.hg.1, the transcript cluster representing all variants of HOXB-AS3 on Affymetrix GeneChip ${ }^{\circ}$ HTA 2.0. The AML patients were stratified into higher- and lower-expression groups with the median expression of $H O X B-A S 3$ as the cutoff level. The $H O X B-A S 3$ levels in the higher-expression group were much higher than those of the healthy donors (Additional file 1: Figure S10; $P<0.000001$ ), while the expression levels were similar between lower group and the healthy donors (Additional file 1: Figure S10). The clinical characteristics of the NTUH AML patients were listed in Additional file 1: Table S1 Patients with higher $H O X B$ $A S 3$ expression were older and had higher frequencies of mutated NPM1/wild FLT3-ITD, MLL-PTD, and RUNX1 mutations, but lower frequency of CEBPAa double mutations than patients with lower expression.

Patients with higher HOXB-AS3 expression had similar complete remission rate to those with lower expression, but had higher relapse rate (Additional file 1: Table S1). With a median follow-up time of 88.1 months, the AML patients with higher $H O X B-A S 3$ expressions had shorter OS and RFS than those with lower HOXB-AS3 expressions (Fig. 4a and $\mathrm{b}$; median OS, 17.7 months versus not reached, $P$ value $<0.0001$; median RFS, 12.9 months versus not reached, $P$ value 0.0070 , respectively). When we stratified patients according to the expression levels of the other transcript cluster representing HOXB-AS3, TC17002254.hg.1, the results were similar (Additional file 1: Figure S11). Subgroup analysis showed that higher HOXB-AS3 expression was also a poor-risk factor for OS in the intermediate-risk cytogenetic group (Fig. 4c). We validated our findings in the TCGA AML cohort in whom higher HOXB-AS3 expression was also an adverse prognostic biomarker (Fig. 4d) [37]. Multivariate analysis showed that higher HOXB-AS3 expression tended to be an independent adverse prognostic factor for OS in AML patients $(P=0.0634$, Table 1$)$.

We further analyzed the patients with AML other than acute promyelocytic leukemia (non-APL), and stratified them according to the median expression of HOXB-AS3 (Additional file 1: Figure S12). Patients with higher $H O X B$ $A S 3$ expression still had shorter OS than those with lower HOXB-AS3 expression (Additional file 1: Figure S13a). The subgroup analysis in the intermediate-risk patients based on the 2017 European LeukemiaNet (ELN) risk classification also illustrated adverse prognosis for the patients with higher HOXB-AS3 expression (Additional file 1: Figure S13b). 


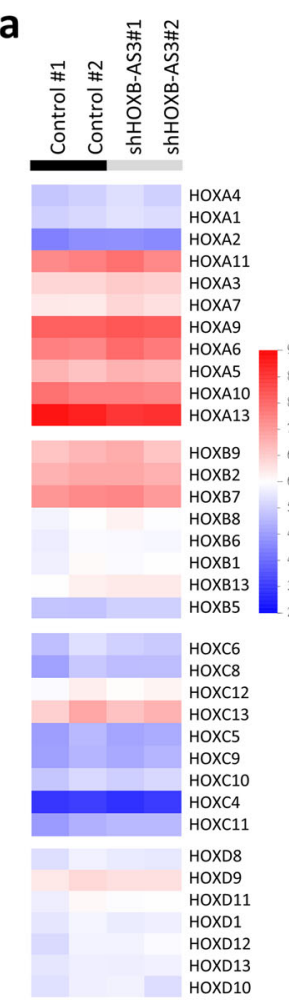

b

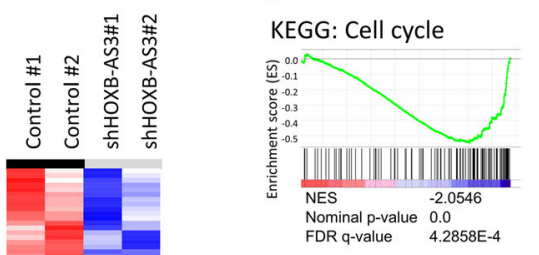

BioCarta: G2 pathway

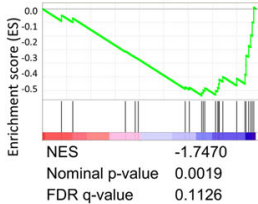

Reactome: Cell cycle

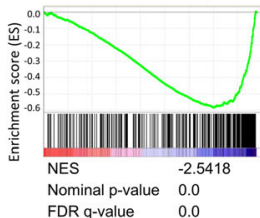

KEGG: DNA replication

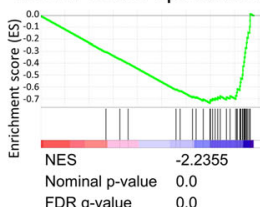

$\begin{array}{ll}\text { Fominal p-value } & 0.0 \\ \text { FDr } & 0.0\end{array}$

Reactome: DNA replication
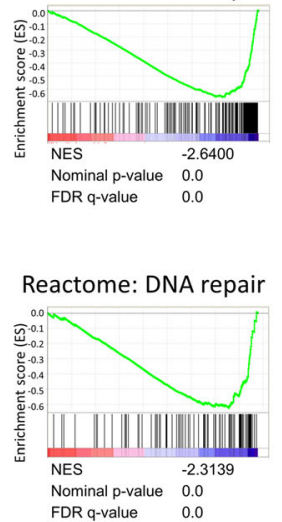

d

OCI/AML3 control $\square$ OCI/AML3 ShHOXB-AS3\#1 $\square$ OCI/AML3 ShHOXB-AS3\#2

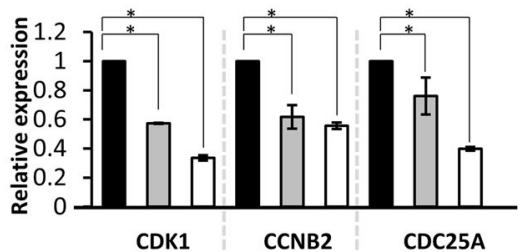

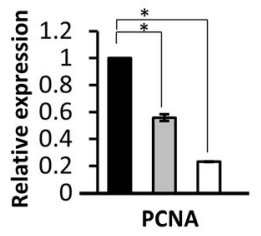

CNA e OCI/AML3

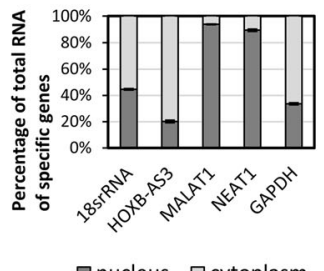

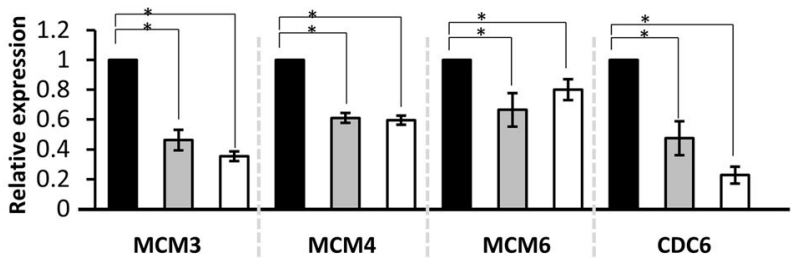

Fig. 3 HOXB-AS3 regulates genes involving in cell cycle progression and DNA replication instead of HOX clusters. a The expressions of HOX genes were not influenced by HOXB-AS3 expression. RNA was purified from OCI/AML3 infected by lentivirus carrying pLKO-shLacZ (control\#1), pLKOvector (control\#2), pLKO-shHOXB-AS3\#1 or pLKO-shHOXB-AS3\#2. b Differentially expressed genes between the control cells and HOXB-AS3 knockdown cells were revealed by microarray analysis. c GSEA analysis of the differentially expressed genes in HOXB-AS3 knockdown cells compared to the control cells. $\mathbf{d}$ Quantitative PCR analysis of the expressions of indicated genes in OCI/AML3 cells infected with lentivirus carrying pLKO-vector (control), shHOXB-AS3\#1, or shHOXB-AS3\#2. Data were derived from the triple repeats of experiments. $P$ values were calculated by Kruskal-Wallis test. e Quantitative real time PCR analysis of RNA18S5 RNA (18s rRNA), HOXB-AS3, MALAT1, NEAT1 and GAPDH in the nuclear and cytoplasmic fractions of OCI/AML3 cells. ( ${ }^{*}$ meant that $P$ value was less than 0.05$)$

\section{Higher HOXB-AS3 expression also predicts adverse prognosis in MDS patients}

To investigate the clinical relevance of $H O X B-A S 3$ expressions in primary MDS, we analyzed the microarrays and clinical data of the NTUH MDS training cohort and validation cohort. $H O X B-A S 3$ expression was determined based on the expression levels of TC17002858.hg.1. According to the expression levels of $H O X B-A S 3$, the MDS patients was stratified into four groups, lowest, intermediate low, intermediate high, and highest $H O X B$ - 

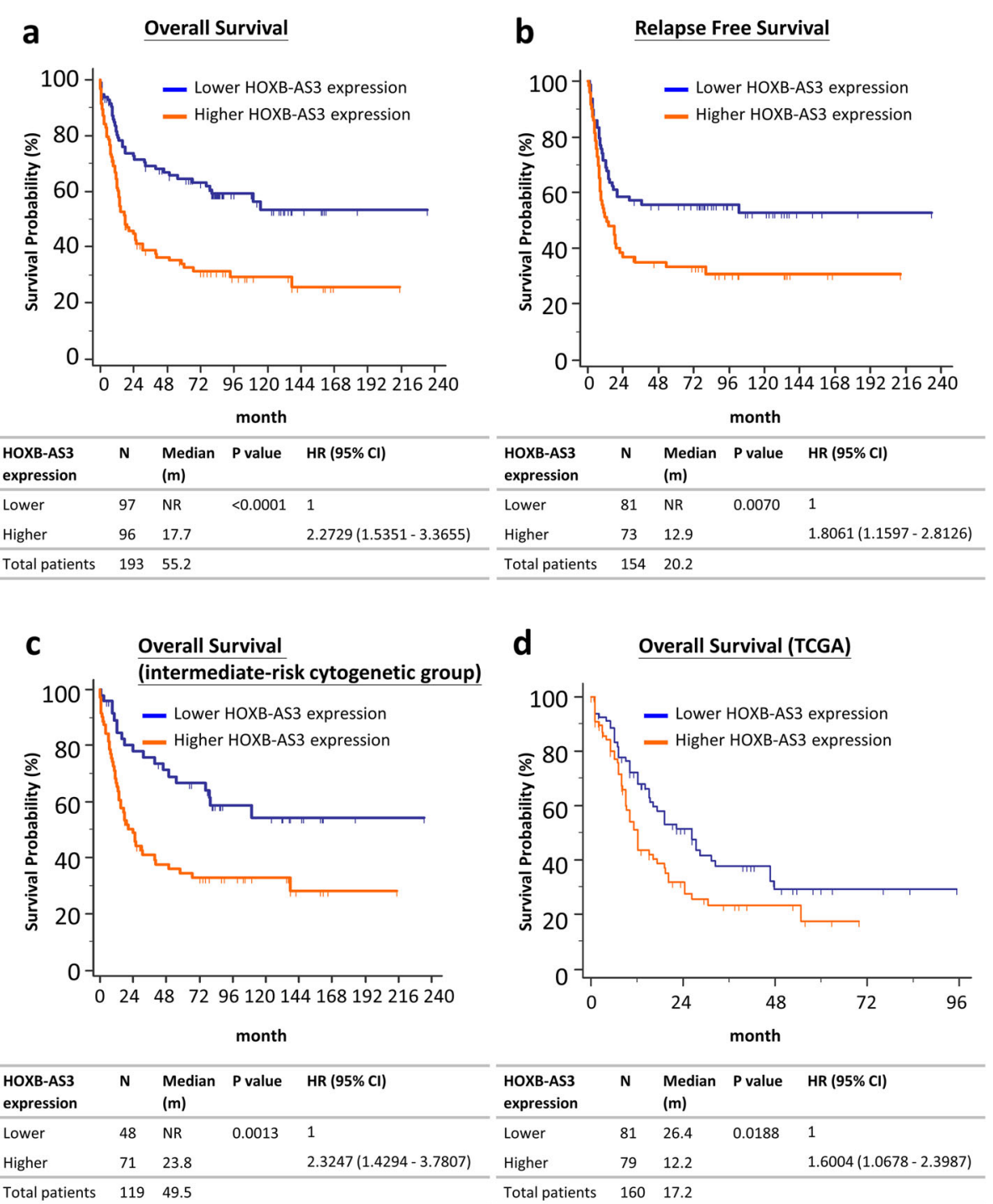

Fig. 4 Survival analysis of de novo AML patients stratified by the expressions of HOXB-AS3. a Overall survival (OS) in the NTUH AML cohort. b Relapse free survival in the NTUH AML cohort. c OS in the AML patients with intermediate-risk cytogenetic changes. d OS in the TCGA AML cohort. The patients in the NTUH AML cohort were stratified by the expressions of transcript cluster: TC17002858.hg.1 on Affymetrix GeneChip ${ }^{\otimes}$ HTA 2.0 arrays

AS3 expression groups (Additional file 1: Figure S14). Only the patients in the highest group had distinct higher $H O X B-A S 3$ expressions compared with the healthy donors (Additional file 1: Figure S14; $P<0.000001$ ), while patients in other groups had similar HOXB-AS3 expressions to normal controls.

With a median follow-up time of 39.2 months, the MDS patients with highest HOXB-AS3 expressions had the shortest OS compared to others (Fig. 5a). The OS was similar among the patients with lowest, intermediate low, and intermediate high expressions of HOXB-AS3. Similar results were obtained when we stratified the patients according to the expressions of another transcript cluster, TC17002254.hg.1, which also represented HOXB-AS3 (Additional file 1: Figure S15a). If we used the cutoff point between the highest and intermediate high groups (Fig. 5a) to stratify the NTUH MDS training cohort into two groups, higher HOXB-AS3 expression predicted shorter OS in the MDS patients (Fig. 5b). The clinical characteristics of the MDS patients were listed in Additional file 1: Table S2, and the correlations of $H O X B-A S 3$ expressions and somatic gene mutations were listed in Additional file 1: Table S3. Patients with higher HOXB-AS3 expression had a high rate of leukemic transformation, higher bone marrow blast percentage and more frequently WHO higher-risk subtypes, but similar distribution of IPSS subtypes, compared to those with lower $H O X B-A S 3$ expression. Higher $H O X B$ $A S 3$ expression was associated with RUNX1, ASXL1, and $I D H 2$ mutations. When we applied the same cutoff point 
Table 1 Univariate and multivariate analyses (Cox regression) for overall survival in AML patients

\begin{tabular}{|c|c|c|c|c|c|c|}
\hline \multirow[t]{2}{*}{ Variables } & \multicolumn{3}{|c|}{ Univariate analysis } & \multicolumn{3}{|c|}{ Multivariate analysis } \\
\hline & $\mathrm{HR}$ & $95 \% \mathrm{Cl}$ & $P$ value & $\mathrm{HR}$ & $95 \% \mathrm{Cl}$ & $P$ value \\
\hline Age $>60$ years & 2.7201 & 1.5917 to 4.6484 & $<0.0001^{*}$ & 2.0425 & 1.2585 to 3.3148 & $0.0038^{*}$ \\
\hline$W B C>100 \mathrm{k} \mu / \mathrm{L}$ & 1.0529 & 0.6026 to 1.8399 & 0.8534 & - & - & - \\
\hline Favorable cytogenetics & 0.4552 & 0.2905 to 0.7133 & $0.0051^{*}$ & 0.4579 & 0.2315 to 0.9058 & $0.0248^{*}$ \\
\hline NPM1+/ FLT3-ITD- & 0.5674 & 0.3346 to 0.9625 & 0.0839 & 0.2972 & 0.1421 to 0.6216 & $0.0013^{*}$ \\
\hline FLT3-TKD & 1.1062 & 0.5419 to 2.2580 & 0.7722 & - & - & - \\
\hline CEBPa double mutation & 0.3093 & 0.1839 to 0.5201 & $0.0030^{*}$ & 0.3893 & 0.1585 to 0.9561 & $0.0396^{*}$ \\
\hline PTPN11 mutation & 1.2426 & 0.5008 to 3.0836 & 0.6042 & - & - & - \\
\hline KRAS mutation & 1.6638 & 0.6351 to 4.3587 & 0.1885 & - & - & - \\
\hline MLL/PTD & 3.5868 & 1.0660 to 12.0688 & $0.0001^{*}$ & 2.3662 & 1.0555 to 5.3047 & $0.0365^{*}$ \\
\hline KIT mutation & 1.0609 & 0.4827 to 2.3319 & 0.8797 & - & - & - \\
\hline RUNX1 mutation & 2.2459 & 1.1285 to 4.4697 & $0.0013^{*}$ & 1.2736 & 0.6998 to 2.3179 & 0.4285 \\
\hline WT1 mutation & 1.4062 & 0.7398 to 2.6728 & 0.2326 & - & - & - \\
\hline ASXL1 mutation & 0.8468 & 0.3932 to 1.8236 & 0.6921 & - & - & - \\
\hline IDH1 mutation & 0.5760 & 0.2364 to 1.4033 & 0.3395 & - & - & - \\
\hline IDH2 mutation & 0.9412 & 0.5109 to 1.7341 & 0.8492 & - & - & - \\
\hline TET2 mutation & 1.1970 & 0.6549 to 2.1879 & 0.5309 & - & - & - \\
\hline TP53 mutation & 4.3752 & 0.5761 to 33.2257 & $0.0015^{*}$ & 3.1834 & 1.0992 to 9.2198 & $0.0328^{*}$ \\
\hline DNMT3A mutation & 1.3679 & 0.8133 to 2.3004 & 0.1908 & - & - & - \\
\hline HOXB-AS3 expression & 2.3003 & 1.5530 to 3.4072 & $<0.0001^{*}$ & 1.6401 & 0.9727 to 2.7654 & 0.0634 \\
\hline
\end{tabular}

Age, elder than 60 years versus younger; WBC, higher than $100 \mathrm{k} \mu / L$ versus lower; HOXB-AS3 expression, higher versus lower; NPM1+/ FLT3-ITD-, mutated NPM1 without FLT3-ITD versus others; other mutations, mutation versus wild type; favorable cytogenetics, favorable versus others

Abbreviations: $H R$ hazard ratio, $C l$ confidence interval, MLL/PTD partial tandem duplication of $M L L$ gene

* $P$ value $<0.05$

to the MDS validation cohort, the prognostic significance of $H O X B-A S 3$ expression for OS in MDS patients was also confirmed (Fig. 5c and Additional file 1: Figure $\mathrm{S} 15 \mathrm{~b})$. Multivariate analysis demonstrated that higher HOXB-AS3 expression was an independent poor prognostic factor for OS in primary MDS patients, irrespective of other poor prognostic factors, including higher IPSS scores and adverse risk mutations (Table 2).

Furthermore, we analyzed prognostic implications of $H O X B-A S 3$ expressions in subgroups of patients with different IPSS risk. Among the patients with IPSS lower risk MDS (low and intermediate-1 risks), those with higher HOXB-AS3 expression had shorter OS than those with lower expression (median, 29.2 months vs 77.3 months, $P$ value 0.0194 ; Fig. $6 \mathrm{a})$. On the other hand, $H O X B-A S 3$ expression did not influence $O S$ in the patients with IPSS higher risk MDS (intermediate- 2 and high risks; Fig. 6b). Therefore, high HOXB-AS3 expression could further identify a subgroup of patients with high risk in the IPSS lower risk group.

\section{Discussion}

In this study, we reported the clinical relevance of lncRNA $H O X B-A S 3$ in de novo AML and primary MDS.
We demonstrated that higher HOXB-AS3 expression was an adverse prognostic factor for AML and MDS patients. To our knowledge, HOXB-AS3 represents the first reported lncRNA whose expression is able to predict the prognosis of MDS patients. We also found that HOXB-AS3 expression could further stratify IPSS lower risk patients into two subgroups with distinct prognosis. This would help us identify the IPSS lower risk patients who need to be treated aggressively.

In addition to identifying the prognostic value of $H O X B-A S 3$ expression in myeloid malignancies, we explored the biological function of HOXB-AS3. We revealed that $H O X B-A S 3$ promoted the proliferation of myeloid cells. Previous studies showed that anti-sense lncRNAs in $H O X$ clusters influence the expressions of HOX genes by trans- or cis-regulation [13, 42, 43]. For examples, HOTAIR trans-regulates the expression of HOXD genes through PRC2 complex [42], whereas HOTAIRM1 cis-regulates the expressions of HOXA1 and HOXA4 genes [13]. Given that expressions of $H O X$ genes are important in cell proliferation, hematopoiesis and leukemogenesis [36, 38, 39], it is possible that $H O X B-A S 3$ promotes cell proliferation by regulating the expressions of certain $H O X$ genes. However, our 

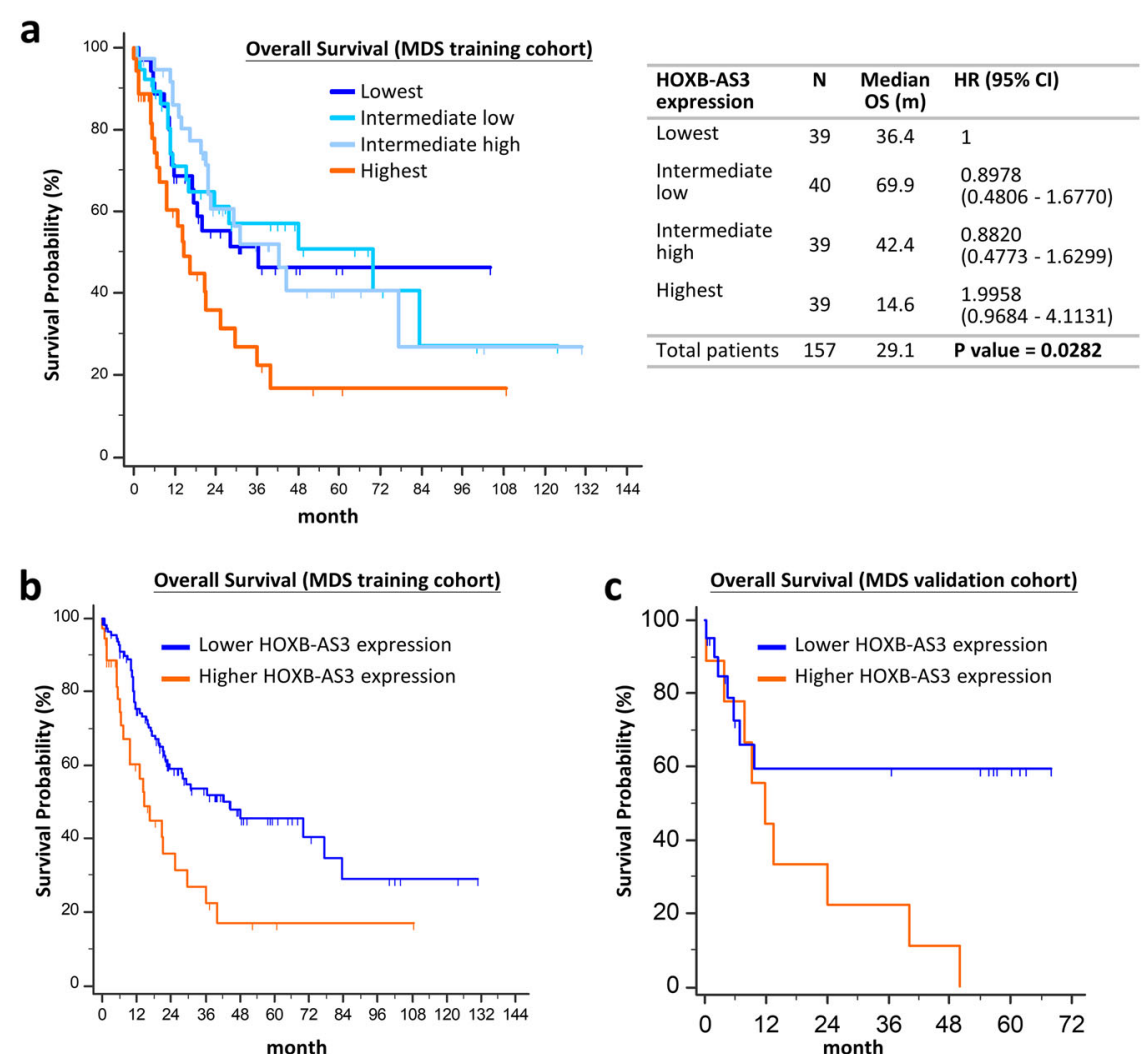

\begin{tabular}{|c|c|c|c|c|c|c|c|c|c|}
\hline $\begin{array}{l}\text { HOXB-AS3 } \\
\text { expression }\end{array}$ & $\mathrm{N}$ & $\begin{array}{l}\text { Median } \\
\text { (m) }\end{array}$ & $P$ value & HR $(95 \% \mathrm{CI})$ & $\begin{array}{l}\text { HOXB-AS3 } \\
\text { expression }\end{array}$ & $N$ & $\begin{array}{l}\text { Median } \\
\text { (m) }\end{array}$ & $P$ value & HR $(95 \% \mathrm{CI})$ \\
\hline Lower & 118 & 42.4 & 0.0018 & 1 & Lower & 21 & NR & 0.0285 & 1 \\
\hline Higher & 39 & 14.6 & & $2.1624(1.1681$ - 4.0033) & Higher & 9 & 11.8 & & $2.8371(0.9852-8.1705)$ \\
\hline Total patients & 157 & 29.1 & & & Total patients & 30 & 13.5 & & \\
\hline
\end{tabular}

Fig. 5 Overall survival of MDS patients stratified by the expressions of HOXB-AS3. a OS in the NTUH MDS training cohort stratified into 4 groups: HOXB-AS3 expression highest, intermediate high, intermediate low and lowest groups. b OS in the NTUH MDS training cohort stratified into 2 groups: HOXB-AS3 expression higher group (HOXB-AS3 expression highest group in Fig. 5a) and lower group (HOXB-AS3 expression lowest, intermediate low, and intermediate high groups in Fig. 5a). c OS in the NTUH MDS validation cohort stratified into 2 groups as Fig. 5b. The patients were stratified by the expressions of transcript cluster: TC17002858.hg.1 on Affymetrix GeneChip ${ }^{\oplus}$ HTA 2.0 arrays

microarray analysis indicated that downregulation of $H O X B-A S 3$ in OCI/AML3 cells did not significantly alter the expression of any $H O X$ gene (Fig. 3a). Instead, $H O X B-A S 3$ potentiated the expressions of a set of genes critical for cell cycle progression and DNA replication (Fig. 3c and Additional file 1: Figure S4), and this finding was consistent with its ability to increase the S-phase cell population (Fig. 2c, e, and g). A recent study showed that knocking down $H O X B-A S 3$ reduces the cells in $\mathrm{S}$ phase and the ability in colony formation, which is consistent with our findings [46]. Further, they demonstrated that $H O X B-A S 3$ binds EBP1 to increase the EBP1-NPM1 complex [46]. Accordingly, overexpression of HOXB-AS3 increases the transcription of rRNA and de novo protein synthesis [46]. This mechanism might explain the effect of $H O X B-A S 3$ on cell proliferation.

The clinical relevance of $H O X B-A S 3$ in hematopoietic diseases remains poorly characterized. A previous study reported a positive correlation of $H O X B-A S 3$ expression with NPM1 mutations in AML patients [47]. In our study, we not only illustrated high $H O X B-A S 3$ expression as a poor prognostic biomarker in AML and MDS, but also disclosed its promotion effect on cell proliferation in two myeloid cell lines (Fig. 2). Further, we showed that higher $H O X B-A S 3$ expression was an adverse prognostic marker in IPSS lower risk patients, but not higher risk ones. It may indicate that higher expressions of $H O X B-A S 3$ influences the prognosis through enhancing proliferation of the abnormal hematopoietic cells in IPSS lower-risk patients, but has no implication when the patients already have many risk factors as in IPSS higher risk patients. These findings imply that $H O X B-A S 3$ may have distinct clinical relevance in different myeloid malignancies.

Of note, a recent study reported that HOXB-AS3 can encode a small peptide to influence the alternative 
Table 2 Univariate and multivariate analyses (Cox regression) for overall survival in MDS patients

\begin{tabular}{|c|c|c|c|c|c|c|}
\hline \multirow[t]{2}{*}{ Variables } & \multicolumn{3}{|c|}{ Univariate analysis } & \multicolumn{3}{|c|}{ Multivariate analysis } \\
\hline & $\mathrm{HR}$ & $95 \% \mathrm{Cl}$ & $P$ value & $\mathrm{HR}$ & $95 \% \mathrm{Cl}$ & $P$ value \\
\hline Age $>60$ years & 1.7988 & 1.1298 to 2.8641 & $0.0223^{*}$ & 1.5433 & 0.8392 to 2.8383 & 0.1628 \\
\hline IPSS & 3.4616 & 1.9730 to 6.0735 & $<0.0001^{*}$ & 2.5755 & 1.4292 to 4.6412 & $0.0016^{*}$ \\
\hline EZH2 mutation & 2.0164 & 0.7036 to 5.7785 & 0.0709 & 1.1877 & 0.4371 to 3.2271 & 0.7358 \\
\hline RUNX1 mutation & 1.6949 & 0.7996 to 3.5925 & 0.0880 & 0.7265 & 0.3155 to 1.6731 & 0.4528 \\
\hline ASXL1 mutation & 1.9909 & 1.0927 to 3.6274 & $0.0059^{*}$ & 1.3616 & 0.6273 to 2.9554 & 0.4350 \\
\hline IDH2 mutation & 1.5777 & 0.2748 to 9.0568 & 0.5195 & - & - & - \\
\hline ZRSR2 mutation & 2.5929 & 1.0588 to 6.3500 & $0.0016^{*}$ & 1.9474 & 0.8973 to 4.2263 & 0.0918 \\
\hline U2AF35 mutation & 1.0584 & 0.4771 to 2.3480 & 0.8861 & - & - & - \\
\hline TET2 mutation & 1.3481 & 0.6591 to 2.7572 & 0.3579 & - & - & - \\
\hline SRSF2 mutation & 1.9654 & 0.9379 to 4.1184 & $0.0196^{*}$ & 1.5304 & 0.7107 to 3.2954 & 0.2769 \\
\hline SF3B1 mutation & 0.7602 & 0.4237 to 1.3640 & 0.3970 & - & - & - \\
\hline TP53 mutation & 7.1283 & 1.2057 to 42.1423 & $<0.001^{*}$ & 6.1091 & 2.3732 to 15.7260 & $0.0002^{*}$ \\
\hline DNMT3A mutation & 1.2781 & 0.6513 to 2.5080 & 0.4344 & - & - & - \\
\hline HOXB-AS3 expression & 2.1624 & 1.1681 to 4.0033 & $0.0018^{*}$ & 1.8992 & 1.0606 to 3.4009 & $0.0309^{*}$ \\
\hline
\end{tabular}

Age, elder than 60 years versus younger; HOXB-AS3 expression, highest versus others; mutations, mutation versus wild type; IPSS, intermediate- 2 and high, versus low and intermediate-1

Abbreviations: $H R$ hazard ratio, $\mathrm{Cl}$ confidence interval

* $P$ value $<0.05$

splicing of pyruvate kinase $M$, thereby inhibiting the proliferation of colon cancer cell lines [48]. In addition, $H O X B-A S 3$ expression is downregulated in colorectal cancer (CRC) tissues and is correlated with favorable prognosis for CRC patients [48]. The seemingly discrepancies between this previous study and our findings are likely due to the different variants of $H O X B-A S 3$ used. The previous study investigated exclusively $H O X B-A S 3$ variant 1 (NR_033201.2), and the small peptide is encoded from the last two exons of this variant [48]. However, in leukemia cell lines, variant 1 is expressed at a very low level, and the majority of $H O X B-A S 3$ transcripts are variants 2/3/5 (Additional file 1: Figure S16), which do not contain the last two exons (Fig. 1b) and therefore cannot encode the small peptide. Because of the abundant expression of variants $2 / 3 / 5$, we used the longest variant, variant 2 , for the overexpression studies and results are consistent with the conclusions derived

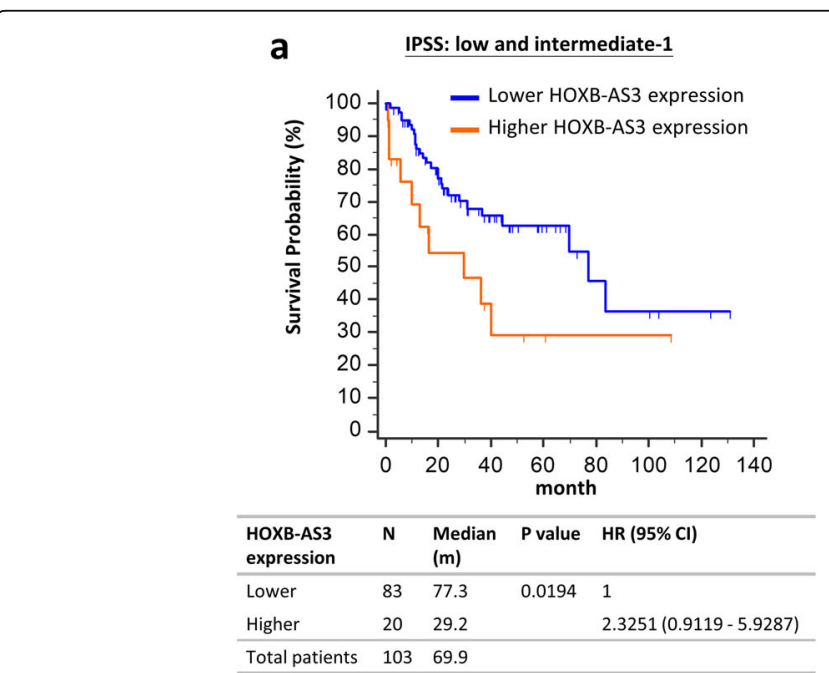

b IPSS: intermediate-2 and high

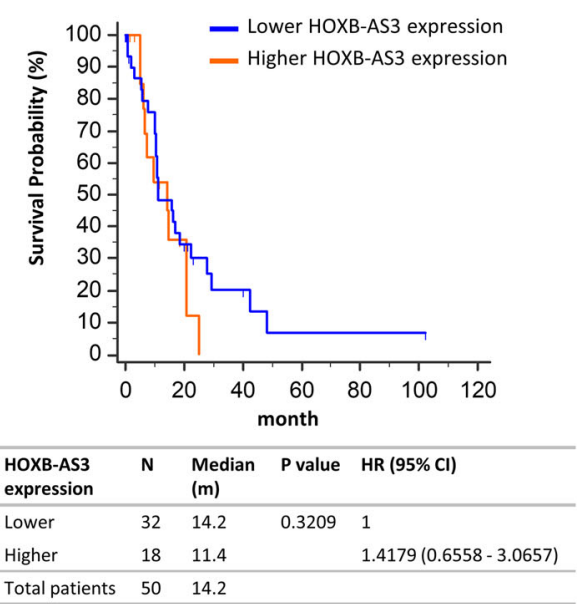

Fig. 6 OS of MDS patients stratified by the expressions of HOXB-AS3 in different IPSS risk groups. a OS in the patients with IPSS low or intermediate-1 risk, stratified by HOXB-AS3 expressions. b OS in the patients with IPSS intermediate-2 or high risk, stratified by HOXB-AS3 expressions. The patients were stratified by the expressions of transcript cluster: TC17002858.hg.1 on Affymetrix GeneChip ${ }^{\oplus}$ HTA 2.0 arrays into 2 groups as Fig. 5b 
from the knockdown studies, in which the two HOXB$A S 3$ shRNAs target variants $2,3,5,8$ and variants 2,3 , $5,6,7,8$, respectively. Therefore, the current and previous studies suggest the existence of variant-specific functions of $H O X B-A S 3$. The relative abundance of $H O X B-A S 3$ variants could determine its contextdependent roles in different cancer types.

\section{Conclusions}

Our study identifies that higher expression of $H O X B$ $A S 3$ is an adverse prognostic marker for both de novo AML and primary MDS patients. Functionally, $H O X B$ $A S 3$ promotes the proliferation of myeloid cells through upregulating the expressions of a set of genes critical for cell cycle progression and DNA replication. HOXB-AS3 can be a potential target for novel therapy in MDS and AML patients with higher $H O X B-A S 3$ expression.

\section{Additional file}

Additional file 1: Table S1. Correlation of HOXB-AS3 expression with clinical characteristics and frequent somatic gene mutations in de novo AML patients. Table S2. Correlation of HOXB-AS3 expression with clinical characteristics in MDS patients. Table S3. Correlation of HOXB-AS3 expression with frequent gene mutations in MDS patients. Figure $\mathbf{S 1 .}$ Overview of Hoxb5os in mouse HOXB cluster. Figure S2. Alignment of mouse Hoxb5os and human HOXB-AS3. Figure S3. HOXB-AS3 promotes $S$ phase entering in the cell cycle regulation. Figure S4. GSEA pathway analysis of the differentially expressed genes in HOXB-AS3 knockdown cells compared to the control cells. Figure S5. Cell cycle pathway from Wikipathway analysis of downstream pathways affected by downregulation of HOXB-AS3 in the myeloid cell lines. Figure S6. DNA replication pathway from Wikipathway analysis of downstream pathways affected by downregulation of HOXB-AS3 in the myeloid cell lines. Figure S7. RB pathway from Wikipathway analysis of downstream pathways affected by downregulation of HOXB-AS3 in the myeloid cell lines. Figure S8. G1-S pathway from Wikipathway analysis of downstream pathways affected by downregulation of HOXB-AS3 in the myeloid cell lines. Figure S9. Quantitative PCR analysis of the expressions of indicated genes in TF-1 cells infected with lentivirus carrying pAS5.1w-Pbsd (control), or pAS5.1W-Pbsd-HOXB-AS3 (HOXB-AS3 overexpression). Figure S10. HOXB-AS3 expressions of AML patients and health donors. Figure S11. Survival analysis of AML patients stratified by the expressions of HOXB-AS3. Figure S12. HOXB-AS3 expression of non-APL AML patients and health donors. Figure S13. Survival analysis of non-APL AML patients stratified by the expressions of HOXB-AS3 in the NTUH AML cohort. Figure S14. HOXBAS3 expressions of MDS patients and health donors. Figure S15. Overall survival of MDS patients stratified by the expressions of HOXB-AS3. Figure S16. Quantitative PCR analysis of the expressions of different variants in TF-1 and OCI/AML3 cell lines. (PDF $2900 \mathrm{~kb}$ )

\footnotetext{
Abbreviations

allo-HSCT: allogeneic hematopoietic stem cell transplantation; AML: Acute myeloid leukemia; APL: Acute promyelocytic leukemia; ATRA: All-trans retinoic acid; BM: Bone marrow; CPAT: Coding Potential Assessment Tool; CR: Complete remission; CRC: Colorectal cancer; ELN: European Leukemia Net; GEO: Gene Expression Omnibus; IPSS: International prognostic scoring system; IPSS-R: Revised international prognostic scoring system; KM: KaplanMeier; IncRNAs: long non-coding RNAs; MDS: Myelodysplastic syndrome; MPN: Myeloproliferative neoplasms; NCBI: National Center for Biotechnology Information; NTUH: National Taiwan University Hospital; OS: Overall survival; RFS: Relapse free survival; TCGA: The Cancer Genome Atlas
}

\section{Acknowledgements}

We would like to acknowledge the service provided by the Flow Cytometric Analyzing and Sorting Core Facility at the National Taiwan University Hospital, the Flow Cytometry Core Facility of the Institute of Biomedical Sciences, Academia Sinica, the Molecular and Immune Function Laboratory at the Tai Cheng Stem Cell Therapy Center, National Taiwan University, and Research Facility of Institute of Biological Chemistry, Academia Sinica, Taiwan.

\section{Author's contributions}

RHC and HFT conceived the project. RHC and HHH designed the experiments. $\mathrm{HHH}$ performed the experiments and analyzed the data. FYC performed the proliferation assay. HHH, RHC, HFT, and WCC wrote the manuscripts. $\mathrm{HHH}, \mathrm{WCC}, \mathrm{HAH}$, and HFT provided the mutation and microarray data of the patients. HHH, HAH, WCC, BSK, CTL, CCL, JLT, MY, WT, SCH, SJW, CYC, SYH, and HFT provided the patients' samples and clinical information. MHT performed the mutation analysis and microarray experiments of patients. All authors have read and approved the final manuscript.

\section{Funding}

This work was funded by the Department of Medical Research, National Taiwan University Hospital, Taiwan. The Grant Number was NTUH.103-M2543, NTUH.104-N2853, NTUH.105-M3277, and NTUH.106-N3704. The funder did not have any role in experimental designs, data analysis or manuscript writing.

\section{Availability of data and materials}

The raw data of TCGA AML cohort was downloaded from TCGA website (https://cancergenome.nih.gov/). The datasets supporting the conclusions of this article are available in NCBI's Gene Expression Omnibus (GEO), and were accessible through GEO Series accession number GSE114823 (https://www. ncbi.nlm.nih.gov/geo/query/acc.cgi?acc=GSE114823), GSE114868 (https:// www.ncbi.nlm.nih.gov/geo/query/acc.cgi?acc=GSE114868), and GSE114869 (https://www.ncbi.nlm.nih.gov/geo/query/acc.cgi?acc=GSE114869).

\section{Ethics approval and consent to participate}

This study was approved by the Institutional Review Board of NTUH (IRB number: 201507084RINA and 201503072RINC). All the patients have signed informed consents for the collection of samples and clinical information.

\section{Consent for publication}

Not applicable.

\section{Competing interests}

The authors declare that they have no competing interests.

\section{Author details}

'Division of Hematology, Department of Internal Medicine, National Taiwan University Hospital, Taipei, Taiwan. ${ }^{2}$ Department of Laboratory Medicine, National Taiwan University Hospital, National Taiwan University, Taipei, Taiwan. ${ }^{3}$ Doctoral Degree Program in Translational Medicine, National Taiwan University and Academia Sinica, Taipei, Taiwan. ${ }^{4}$ Institute of Biological Chemistry, Academia Sinica, Taipei, Taiwan. ${ }^{5}$ Taicheng Stem Cell Therapy Center, National Taiwan University, Taipei, Taiwan.

Received: 24 July 2018 Accepted: 12 June 2019

Published online: 24 June 2019

\section{References}

1. Arber DA, Orazi A, Hasserjian R, Thiele J, Borowitz MJ, Le Beau MM, et al. The 2016 revision to the World Health Organization classification of myeloid neoplasms and acute leukemia. Blood. 2016;127:2391-405.

2. Larsson CA, Cote G, Quintas-Cardama A. The changing mutational landscape of acute myeloid leukemia and myelodysplastic syndrome. Mol Cancer Res. 2013;11:815-27.

3. Dohner H, Estey E, Grimwade D, Amadori S, Appelbaum FR, Buchner T, et al. Diagnosis and management of AML in adults: 2017 ELN recommendations from an international expert panel. Blood. 2017;129:424-47.

4. Greenberg P, Cox C, LeBeau MM, Fenaux P, Morel P, Sanz G, et al. International scoring system for evaluating prognosis in myelodysplastic syndromes. Blood. 1997;89:2079-88. 
5. Voso MT, Fenu S, Latagliata R, Buccisano F, Piciocchi A, Aloe-Spiriti MA, et al. Revised international prognostic scoring system (IPSS) predicts survival and leukemic evolution of myelodysplastic syndromes significantly better than IPSS and WHO prognostic scoring system: validation by the Gruppo Romano Mielodisplasie Italian regional database. J Clin Oncol. 2013;31:2671-7.

6. Malcovati L, Porta MG, Pascutto C, Invernizzi R, Boni M, Travaglino E, et al. Prognostic factors and life expectancy in myelodysplastic syndromes classified according to WHO criteria: a basis for clinical decision making. J Clin Oncol. 2005;23:7594-603.

7. Neukirchen J, Lauseker M, Blum S, Giagounidis A, Lubbert M, Martino S, et al. Validation of the revised international prognostic scoring system (IPSS-R) in patients with myelodysplastic syndrome: a multicenter study. Leuk Res. 2014:38:57-64

8. Schanz J, Tuchler H, Sole F, Mallo M, Luno E, Cervera J, et al. New comprehensive cytogenetic scoring system for primary myelodysplastic syndromes (MDS) and oligoblastic acute myeloid leukemia after MDS derived from an international database merge. J Clin Oncol. 2012;30:820-9.

9. Estey E. Acute myeloid leukemia: 2016 update on risk-stratification and management. Am J Hematol. 2016;91:824-46.

10. Bejar R. Clinical and genetic predictors of prognosis in myelodysplastic syndromes. Haematologica. 2014;99:956-64.

11. Hou HA, Tsai CH, Lin CC, Chou WC, Kuo YY, Liu CY, et al. Incorporation of mutations in five genes in the revised international prognostic scoring system can improve risk stratification in the patients with myelodysplastic syndrome. Blood Cancer J. 2018;8:39.

12. Alhan C, Westers TM, Cremers EM, Cali C, Witte BI, Ossenkoppele GJ, et al. The myelodysplastic syndromes flow cytometric score: a three-parameter prognostic flow cytometric scoring system. Leukemia. 2016;30:658-65.

13. Zhang X, Lian Z, Padden C, Gerstein MB, Rozowsky J, Snyder M, et al. A myelopoiesis-associated regulatory intergenic noncoding RNA transcript within the human HOXA cluster. Blood. 2009;113:2526-34.

14. Zeng $C, X u Y, X u L, Y u X$, Cheng J, Yang $L$, et al. Inhibition of long noncoding RNA NEAT1 impairs myeloid differentiation in acute promyelocytic leukemia cells. BMC Cancer. 2014;14:693.

15. Yildirim E, Kirby JE, Brown DE, Mercier FE, Sadreyev RI, Scadden DT, et al. Xist RNA is a potent suppressor of hematologic cancer in mice. Cell. 2013;152:727-42.

16. Yao CY, Chen CH, Huang HH, Hou HA, Lin CC, Tseng MH, et al. A 4-IncRNA scoring system for prognostication of adult myelodysplastic syndromes. Blood Adv. 2017;1:1505-16.

17. Wang $X$, Zhang L, Zhao F, Xu R, Jiang J, Zhang C, et al. Long non-coding RNA taurine-upregulated gene 1 correlates with poor prognosis, induces cell proliferation, and represses cell apoptosis via targeting aurora kinase a in adult acute myeloid leukemia. Ann Hematol. 2018;97:1375-89.

18. Mer AS, Lindberg J, Nilsson C, Klevebring D, Wang M, Gronberg H, et al. Expression levels of long non-coding RNAs are prognostic for AML outcome. J Hematol Oncol. 2018;11:52.

19. Huang JL, Liu W, Tian LH, Chai TT, Liu Y, Zhang F, et al. Upregulation of long non-coding RNA MALAT-1 confers poor prognosis and influences cel proliferation and apoptosis in acute monocytic leukemia. Oncol Rep. 2017; 38:1353-62.

20. Hou HA, Kuo YY, Liu CY, Chou WC, Lee MC, Chen CY, et al. DNMT3A mutations in acute myeloid leukemia: stability during disease evolution and clinical implications. Blood. 2012;119:559-68.

21. Chou WC, Tang JL, Wu SJ, Tsay W, Yao M, Huang SY, et al. Clinical implications of minimal residual disease monitoring by quantitative polymerase chain reaction in acute myeloid leukemia patients bearing nucleophosmin (NPM1) mutations. Leukemia. 2007;21:998-1004.

22. Cheng CL, Hou HA, Lee MC, Liu CY, Jhuang JY, Lai YJ, et al. Higher bone marrow LGALS3 expression is an independent unfavorable prognostic factor for overall survival in patients with acute myeloid leukemia. Blood. 2013;121:3172-80.

23. Tien HF, Wang CH, Lin MT, Lee FY, Liu MC, Chuang SM, et al. Correlation of cytogenetic results with immunophenotype, genotype, clinical features, and ras mutation in acute myeloid leukemia. A study of 235 Chinese patients in Taiwan. Cancer Genet Cytogenet. 1995;84:60-8.

24. Chiu YC, Tsai MH, Chou WC, Liu YC, Kuo YY, Hou HA, et al. Prognostic significance of NPM1 mutation-modulated microRNA-mRNA regulation in acute myeloid leukemia. Leukemia. 2016;30:274-84.

25. Chen CY, Lin LI, Tang JL, Ko BS, Tsay W, Chou WC, et al. RUNX1 gene mutation in primary myelodysplastic syndrome--the mutation can be detected early at diagnosis or acquired during disease progression and is associated with poor outcome. Br J Haematol. 2007;139:405-14.
26. Chou WC, Huang HH, Hou HA, Chen CY, Tang $J$, Yao M, et al. Distinct clinical and biological features of de novo acute myeloid leukemia with additional sex comb-like 1 (ASXL1) mutations. Blood. 2010;116:4086-94.

27. Ernst T, Chase AJ, Score J, Hidalgo-Curtis CE, Bryant C, Jones AV, et al. Inactivating mutations of the histone methyltransferase gene $\mathrm{EZH} 2$ in myeloid disorders. Nat Genet. 2010;42:722-6.

28. Chou WC, Lei WC, Ko BS, Hou HA, Chen CY, Tang JL, et al. The prognostic impact and stability of Isocitrate dehydrogenase 2 mutation in adult patients with acute myeloid leukemia. Leukemia. 2011;25:246-53.

29. Chen CY, Lin LI, Tang JL, Tsay W, Chang HH, Yeh YC, et al. Acquisition of JAK2, PTPN11, and RAS mutations during disease progression in primary myelodysplastic syndrome. Leukemia. 2006;20:1155-8.

30. Hou HA, Chou WC, Kuo YY, Liu CY, Lin LI, Tseng MH, et al. TP53 mutations in de novo acute myeloid leukemia patients: longitudinal follow-ups show the mutation is stable during disease evolution. Blood Cancer J. 2015;5:e331.

31. Hou HA, Kuo YY, Tang JL, Chou WC, Yao M, Lai YJ, et al. Clinical implications of the SETBP1 mutation in patients with primary myelodysplastic syndrome and its stability during disease progression. Am J Hematol. 2014;89:181-6.

32. Wu SJ, Kuo YY, Hou HA, Li LY, Tseng MH, Huang CF, et al. The clinical implication of SRSF2 mutation in patients with myelodysplastic syndrome and its stability during disease evolution. Blood. 2012;120:3106-11.

33. Chou WC, Chou SC, Liu CY, Chen CY, Hou HA, Kuo YY, et al. TET2 mutation is an unfavorable prognostic factor in acute myeloid leukemia patients with intermediate-risk cytogenetics. Blood. 2011;118:3803-10.

34. Shiah HS, Kuo YY, Tang JL, Huang SY, Yao M, Tsay W, et al. Clinical and biological implications of partial tandem duplication of the MLL gene in acute myeloid leukemia without chromosomal abnormalities at 11q23. Leukemia. 2002:16:196-202.

35. Hou HA, Liu CY, Kuo YY, Chou WC, Tsai CH, Lin CC, et al. Splicing factor mutations predict poor prognosis in patients with de novo acute myeloid leukemia. Oncotarget. 2016;7:9084-101.

36. Lebert-Ghali CE, Fournier M, Kettyle L, Thompson A, Sauvageau G, Bijl JJ. Hoxa cluster genes determine the proliferative activity of adult mouse hematopoietic stem and progenitor cells. Blood. 2016;127:87-90.

37. Cancer Genome Atlas Research N, Ley TJ, Miller C, Ding L, Raphael BJ, Mungall AJ, et al. Genomic and epigenomic landscapes of adult de novo acute myeloid leukemia. N Engl J Med. 2013;368:2059-74.

38. Guenther MG, Jenner RG, Chevalier B, Nakamura T, Croce CM, Canaani E, et al. Global and Hox-specific roles for the MLL1 methyltransferase. Proc Natl Acad Sci U S A. 2005;102:8603-8.

39. Bach C, Buhl S, Mueller D, Garcia-Cuellar MP, Maethner E, Slany RK. Leukemogenic transformation by HOXA cluster genes. Blood. 2010;115: 2910-8.

40. Diaz-Beya M, Brunet S, Nomdedeu J, Pratcorona M, Cordeiro A, Gallardo D, et al. The lincRNA HOTAIRM1, located in the HOXA genomic region, is expressed in acute myeloid leukemia, impacts prognosis in patients in the intermediate-risk cytogenetic category, and is associated with a distinctive microRNA signature. Oncotarget. 2015;6:31613-27.

41. Lin MF, Jungreis I, Kellis M. PhyloCSF: a comparative genomics method to distinguish protein coding and non-coding regions. Bioinformatics. 2011;27: i275-82.

42. Rinn JL, Kertesz M, Wang JK, Squazzo SL, Xu X, Brugmann SA, et al. Functional demarcation of active and silent chromatin domains in human HOX loci by noncoding RNAs. Cell. 2007;129:1311-23.

43. Wang KC, Yang YW, Liu B, Sanyal A, Corces-Zimmerman R, Chen Y, et al. A long noncoding RNA maintains active chromatin to coordinate homeotic gene expression. Nature. 2011:472:120-4.

44. Tripathi V, Ellis JD, Shen Z, Song DY, Pan Q, Watt AT, et al. The nuclear-retained noncoding RNA MALAT1 regulates alternative splicing by modulating SR splicing factor phosphorylation. Mol Cell. 2010;39: 925-38.

45. West JA, Davis CP, Sunwoo H, Simon MD, Sadreyev Rl, Wang Pl, et al. The long noncoding RNAs NEAT1 and MALAT1 bind active chromatin sites. Mol Cell. 2014:55:791-802.

46. Dimitrios Papaioannou AP, Terreri S, Thrue CA, Nicolet D, Collins FA, Woodward LA, Kumchala P, Karunasiri M, Pepe F, Bill M, Zitzer N, Singh G, Kaupinnen S, Bloomfield CD, Dorrance AM, Garzon R. The long non-coding RNA (IncRNA) HOXB-AS3 regulates transcription of ribosomal RNA (rRNA) in NPM1-mutated (NPM1mut) acute myeloid leukemia (AML)[abstract]. In: American Association for Cancer Research Annual Meeting 2018; 2018 Apr 14-18; Chicago, IL. Philadelphia (PA). Cancer Research; 2018. Abstract nr 519. 
47. Garzon R, Volinia S, Papaioannou D, Nicolet D, Kohlschmidt J, Yan PS, et al. Expression and prognostic impact of IncRNAs in acute myeloid leukemia. Proc Natl Acad Sci U S A. 2014;111:18679-84.

48. Huang JZ, Chen M, Chen GXC, Zhu S, Huang H, et al. A peptide encoded by a putative IncRNA HOXB-AS3 suppresses Colon Cancer growth. Mol Cell. 2017;68:171-184 e176.

\section{Publisher's Note}

Springer Nature remains neutral with regard to jurisdictional claims in published maps and institutional affiliations.

- fast, convenient online submission

- thorough peer review by experienced researchers in your field

- rapid publication on acceptance

- support for research data, including large and complex data types

- gold Open Access which fosters wider collaboration and increased citations

- maximum visibility for your research: over $100 \mathrm{M}$ website views per year

At $\mathrm{BMC}$, research is always in progress. 